\title{
NOMMENSEN DAN PARIWISATA ROHANI SALIB KASIH TARUTUNG
}

\author{
Roy J. M. Hutagalung \\ Institut Agama Kristen Negeri Tarutung \\ Email: hutagalungjuan0@gmail.com
}

\begin{abstract}
ABSTRAK- Artikel ini merupakan kajian pustaka yang diolah menjadi suatu informasi dalam mengungkap Nommensen dikenang dengan pariwisata rohani Salib Kasih Tarutung. Hasil kajian ini menunjukkan bahwa dari segi daya tarik atau atraksi wisata maka wisata religi tergolong kepada buatan manusia (Man made), manusia membuat tempat pariwisata, atau dalam hal ini keperdulian pemerintah kabupaten tapanuli utara membangun monumen, untuk mengenang misionaris Kristen yang bernama Nommensen tujuannya disamping untuk mengenang peristiwa penyebaran agama Kristen di tanah Batak tetapi juga sebagai tempat pariwisata.
\end{abstract}

Kata kunci: Nommensen, pariwisata rohani, salib kasih

\section{PENDAhuluan}

Di Indonesia, industri pariwisata merupakan salah satu pusat perhatian pemerintah yang diharapkan dapat dijadikan salah satu aspek usaha peningkatan devisa Negara (Rithaony 1997:15). Di samping untuk peningkatan devisa Negara juga untuk kesejahteraan ekonomi masyarakatnya. Tujuannya adalah untuk menyebar luaskan kesempatan kerja bagi masyarakat Indonesia dan memperkenalkan kebudayaan etnik Indonesia ke dunia luar (Pendit 1984:64). Yang di perjelas dalam Rencana Pembangunan Lima Tahun ke-5 (Repelita V) dan dalam Garis-garis Besar Haluan Negara 1988 (GBHN 1988) yang menyatakan bahwa tujuan pariwisata adalah untuk mempromosikan dan mengembangkan kebudayaan nasional Indonesia.

Objek wisata merupakan salah satu langkah bijak pemerintah yang harus lebih ditingkatkan lagi tentunya dalam mengenalkan budaya, keindahan alam dan juga didalam hal peningkatan ekonomi yang punya tempat wisata. Obyek wisata adalah salah satu komponen yang penting dalam industri pariwisata dan salah satu alasan pengunjung melakukan perjalanan (something to see). Di luar negeri obyek wisata disebut tourist atraction (atraksi wisata), sedangkan di Indonesia lebih dikenal dengan objek wisata. Mengenai pengertian objek wisata, kita dapat melihat dari beberapa sumber antara lain:

1. Surat Keputusan Departemen Pariwisata, Pos, dan Telekomunikasi No.KM 98/PW:102/MPPT-87.

2. Peraturan Pemerintah No.24/1979. Objek wisata adalah perwujudan dari ciptaan manusia, tata hidup, seni budaya serta sejarah bangsa dan tempat keadaan alam yang mempunyai daya tarik untuk dikunjungi.

Perlu kita ketahui perbedaan antara wisatawan dan pariwisata, wisatawan adalah orang yang melakukan 
kegiatan wisata, sedangkan pariwisata adalah segala sesuatu yang berhubungan dengan wisata, termasuk pengusahaan obyek dan daya tarik wisata serta usahausaha yang terkait di bidang tersebut (Undang-Undang No.9 Tahun 1990 tentang Kepariwisataan).

Pengertian Daya Tarik Wisata

menurut Undang-undang Republik Indonesia No. 10 tahun 2009 tentang Kepariwisataan Bab I, pasal 5, menyebutkan sebagai berikut "daya tarik wisata" adalah segala sesuatu yang memiliki keunikan, keindahan, dan nilai yang berupa keanekaragaman kekayan alam, budaya dan hasil buatan manusia yang menjadi sasaran atau tujuan kunjungan wisatawan. Dan juga Daya tarik atau atraksi wisata menurut Yoeti (1996) adalah segala sesuatu yang dapat menarik wisatawan untuk berkunjung pada suatu daerah tujuan wisata, seperti:

a. Alam (Nature), yaitu segala sesuatu yang berasal dari alam yang dimanfaatkan dan diusahakan di tempat objek wisata yang dapat dinikmati dan memberikan kepuasan kepada wisatawan. Contohnya, pemandangan alam, pegunungan, flora dan fauna.

b. Budaya (Culture), yaitu segala sesuatu yang berupa daya tarik yang berasal dari seni dan kreasi manusia. Contohnya, upacara keagamaan, upacara adat dan tarian tradisional.

c. Buatan Manusia (Man made), yaitu segala sesuatu yang berasal dari karya manusia, dan dapat dijadikan sebagai objek wisata seperti benda-benda sejarah, kebudayaan, religi serta tata cara manusia.

d. Manusia (Human being), yaitu segala sesuatu dari aktivitas manusia yang khas dan mempunyai daya tarik tersendiri yang dapat dijadikan sebagi objek wisata. Contohnya, Suku Asmat di
Irian Jaya dengan cara hidup mereka yang masih primitif dan memiliki keunikan tersendiri.

Dari segi daya tarik atau atraksi wisata maka wisata religi tergolong kepada buatan manusia (Man made) manusia membuat tempat pariwisata, dalam hal ini keperdulian pemerintah kabupaten tapanuli utara membangun monumen, untuk mengenang misionaris Kristen yang bernama Nommensen tujuannya disamping untuk mengenang peristiwa penyebaran agama Kristen di tanah Batak tetapi juga sebagai tempat pariwisata, maka pemerintah tapanuli utara membangun monumen yang dinamai pariwisata Salib Kasih Tarutung.

Wisata religi merupakan salah satu fenomena yang saat ini mulai memasyarakat, hal itu dibuktikannya banyak aktifitas atau kegiatan yang dikaitkan dengan wisata religi, tidak terkecuali seperti wisatawan yang ingin melihat langsung tempat Nommensen pertama kali berdoa setelah tiba di tanah Batak yaitu di kecamatan siatas barita desa simorangkir julu tempat didirikannya Salib Kasih Tarutung.

Di beberapa gereja, sekolah atau kelompok masyarakat, pariwisata Salib Kasih Tarutung ini sering dijadikan sebagai kegiatan rutinan baik bulanan, tahunan dan sebagainya. Hal itu dilakukan sebagai pengisi agenda dari kegiatan atau rutinitas kunjungan beribadah dan juga akan mendapatkan pelajaran tentang ajaran-ajaran Kristen serta menambah pengetahuan dan wawasan sejarah tentang Nommensen.

Dari beberapa penjelasan diatas muncul pertanyaan, bagaimana dan tantangan apa saja yang dilalui Nommensen di dalam menyebarkan agama Kristen di tanah Batak, sehingga pemerintah dan masyarakat dan juga elemen pendukungnya beranggapan 
bahwa, peristiwa itu begitu besar didalam penyebaran agama Kristen khususnya di tanah Batak Toba, sehingga dianggap perlu oleh pemerintah Kabupaten Tapanuli utara untuk membangun monumen Salib Kasih sebagai simbol untuk mengenang Nommensen.

\section{METODE}

Penelitian ini menggunakan pendekatan penelitian kualitatif deskriptif dikarenakan variabel penelitian merupakan objek yang tidak perlu menggunakan pengukuran dan proses statistik. Menurut Moleong (2001: 6),data penelitian kualitatif yang dikumpulkan adalah data yang berupa kata-kata, gambar,dan bukan merupakan angka-angka. Penelitian ini bertujuan untuk mendeskripsikan bahwa Salib kasih didirikan untuk mengenang peristiwa penyebaran agama Kristen di rintis di tanah Batak yang dirintis oleh misionaris asal jerman, tokoh Kristen yang bernama Dr. Ludwig Ingwer Nommensen di Batak Toba yang terletak di provinsi Sumatera utara kabupaten tapanuli utara, ibukota Tarutung, kecamatan siatas barita desa simorangkir julu. Artikel ini merupakan kajian pustaka yang diolah menjadi suatu informasi dalam mengungkap Nommensen dan pariwisata rohani Salib Kasih Tarutung.

Di dalam mengungkap ini juga diperlukan kajian tentang sejarah. Kajian sejarah yang penulis maksud disini tidak lagi membahas tentang pengaruh gereja terhadap kebudayaan sosial masyarakat Batak Toba, pembagian wilayah, pemerintahan, budaya, perdagangan, kehidupan keseharian, bahasa dan system kepercayaan orang Batak Toba. Dalam tulisan ini kajian sejarah yang penulis maksud di bagi menjadi : 1.Masa
Perjanjian Nommensen Menjadi Penginjil (1834), 2. Masa Nommensen Memulai Misi Penginjilan (1861), 3. Masa Penginjilan Nommensen di Tanah Batak (1864), 4. Masa Akhir Pengabdian Nommensen (1880 -1918).

\section{PEMBAHASAN}

\subsection{Dr. Ludwig Ingwer Nommensen} (6 February 1834 -23 May 1918)

\subsubsection{Masa Perjanjian Nommensen Menjadi Penginjil}

Ingwer Ludwig Nommensen

lahir 6 February 1834 di Noordstrand, sebuah pulau kecil di Jerman. Anak lakilaki ini lahir dalam keluarga yang miskin dan menderita.Hidup mereka sangat melarat.Ayahnya sakit-sakitan (Hotmaida 1993:1).Demikian salah satu kutipan tentang riwayat I.L. Nommensen, sebelum dia menjadi tokoh Kristen yang sangat populer di Tanah Batak. Dari beberapa gambaran peristiwa ketika Nommensen masih kecil ada peristiwa pada tahun 1846, saat berusia 12tahun, Nommensen mengalami kecelakaan, waktu itu ia bermain kejarkejaran dengan temannya, ia ditabrak kereta kuda yang menggilas kakinya sampai patah dan keadaan yang demikian memaksanya berbaring di tempat tidur berbulan-bulan lamanya. Waktu itu, dalam doanya, Nommensen meminta kesembuhan dan berjanji, jika ia disembuhkan, maka ia akan memberitakan injil kepada orang kafir, setelah kakinya sembuh, Nommensen kembali menjadi buruh tani untuk membantu keluarganya setelah kematian ayahnya.

Nommensen menepati janjinya, pada usia 20 tahun, Nommensen berangkat ke barmen (sekarang Wuppertal) dia melamar menjadi 
penginjil seperti yang sudah dijanjikannya, selama kurang-lebih empat tahun ia belajar di seminari zending Lutheran Rheinische Missionsgesellschaft (RMG). Kemudian setelah lulus, ia kemudian ditahbiskan menjadi pendeta pada tahun 1861. Nommensen ditugaskan pertama sekali oleh RMG ke Sumatra dan dia tiba pada tanggal 14 Mei 1862 di Padang.

\subsubsection{Masa Nommensen Memulai Misi Penginjilan}

Nommensen berangkat ke negeri Belanda untuk menerima tugas dari Pendeta Witteveen.Pada 24 Desember 1861 berangkat menuju Pulau Sumatera yang saat itu bernama Morsa.Dengan menumpang kapal Pertinax dari Eropa, setelah mengarungi lautan selama 142 hari, akhirnya mereka tiba di padang, tepatnya 16 Mei 1862 . Tanggal 16 Juni 1862 , Nommensen meninggalkan padang menuju sibolga dan seterusnya di barus dan tinggal disana selama 6 bulan, tetapi karena waktu itu Parau Sorot ada masalah, maka dia melanjutkan perjalanannya ke daerahsilindung yang menjadi cita-citanya dari awal, tepatnya pada 7 November 1863.

Dalam perjalananya melewati Simangambat, Sigotom, Liang, Banjarnahor, dan pada siang hari tiba di bukit Siatasbarita.Dari sanalah dia memandang dan menyaksikan betapa indahnya Rura Silindung. Beberapa jam lamanya dia memandang Rura Silindung, baru ia berdoa, "Hidup atau Mati, aku tinggal ditengah-tengah bangsa ini, berdiam memberitakan firman-Mu" (Arifin 2011:39).

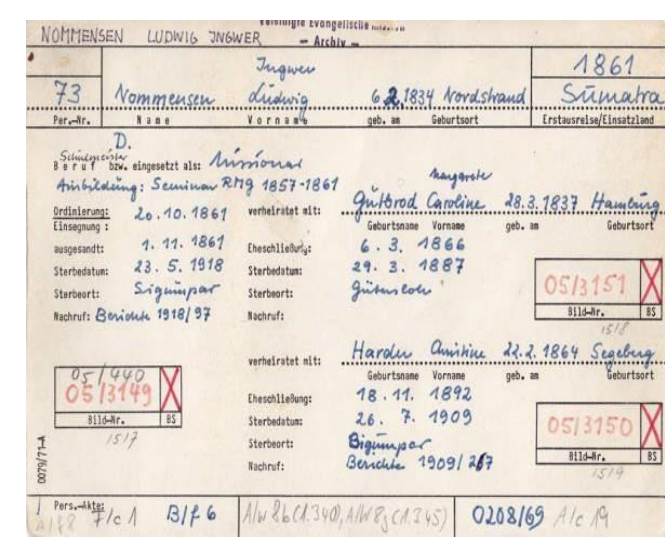

Kartu Pegawai Dr. Ingwer Ludwig Nommensen Dari Norsdtrand ke Silindung

http://batakculture.wordpress.com/20 12/05/08/

\subsubsection{Tantangan dan Strategi Penginjilan Nommensen di Tanah Batak}

Nommensen memulai misinya di Barus dengan harapan akan mendapatkan izin untuk menetap di daerah Toba akan tetapi pemerintah kolonial tidak mengizinkan dengan alasan keamanan. Oleh sebab itu, ia bergabung dengan penginjil-penginjil lain yaitu misionaris Pdt. Heyni dan Pdt. Klammer yang telah berada di daerah Sipirok yangsetelah PerangPadri dimasukkan dalam wilayah Hindia Belanda. Pada masa itu, sebagian dari penduduk sudah memeluk agama Islam sehingga kemajuannya lambat. Setelah berdiskusi dengan kedua misionaris ini, disepakati pembagian wilayah pelayanan, bahwa Nommensen akan bekerja di Silindung.

Van Asselt, Heine, Betz dan Klammer yang mengadakan rapat pendeta pada 7 Oktober 1861 di Sipirok untuk mengatur strategi PI. Kemudian dilanjutkan oleh Nommensen, Schreiber, Johansen dkk sejak tahun 1862.Selanjutnya Nommensen 
melanjutkan perjalanannya ke Sait Ni Huta, melalui Hutagalung dan tiba di Hutabagasan.

Kunjungan pertama

ke Tarutung dilakukan pada 11 November 1863.Pada kunjungan pertama ini, Nommensen diterima oleh Ompu Pasang (Ompu Tunggul) kemudian tinggal di rumahnya yang daerahnya masuk dalam kekuasaan Raja Pontas Lumban Tobing.Dari sini Nommensen kemudian kembali ke Sipirok untuk mempersiapkan segala sesuatunya yang diperlukan dalam pelayanannya.

Pada pertengahan tahun berikutnya, 1864, Nommensen dengan membawa semua perlengkapannya berangkat kembali ke Tarutung, dan tiba di Tarutung pada tanggal 7 Mei 1864.Nommensen kembali ke rumah Ompu Pasang (Ompu Tunggul), tetapi dia ditolak.

Semasa penolakan Nommensen tinggal di Onan Sitahuru dan menumpang di Sopo Raja Ompu Tunggal, tidak berapa lama Nommensen tinggal di Sopo tersebut, karena dengan segala macam cara dan alasan oleh rajaraja setempat untuk menolak kehadiran Nommensen di tempat itu, dan memang pada waktu itu sedang panen padi, jadi sopo perlu untuk tempat padi.Di Onan Sitahuru, Nommensen duduk dan merenung di bawah sebatang pohon beringin (hariara) untuk memikirkan apa yang akan dia perbuat. Nommensen lalu pergi ke desa lain dan sampai di desa Raja Aman Dari Lumban Tobing.

Berita tentang Nommensen sampai ke telinga Raja Amandari, salah satu raja dari pomparan O Sumurung dan beliau menyuruh salah seorang pembantunya yaitu Pandjingkel Silalahi untuk menyampaikan kepada Nommensen bahwa dia tidak di terima di Hutabagasan. Nommensen berharap Raja
Amandari Lumbantobing dapat mengizinkannya tinggal di atas lumbung padinya. Akan tetapi Raja Aman dari Lumbantobing sedang pergi kedesa lain membawa isterinya yang sedang sakit keras. Melalui seorang utusan, Nommensen menyampaikan niatnya ini kepada Raja Aman Lumbantobing, akan tetapi Raja Aman Lumbantobing menolak. Nommensen kemudian meminta utusannya ini untuk kembali menemui Raja Aman Lumbantobing untuk kedua kalinya dengan pesan, "bahwa sekembalinya Raja Aman ke desanya, penyakit istrinya akan hilang". Raja Aman kemudian berkata, apabila perkataan Nommensen itu benar, maka dia akan mengizinkan Nommensen tinggal dirumahnya. Penyakit istri Raja Aman sembuh.Raja Aman Lumbantobing kemudian mengizinkan Nommensen tinggal di rumahnya.

Raja Amandari bersedia menerima beliau di Huta Nabolon Sait Ni Huta, O Sumurung mendengar berita ini sangat gembira dan langsung membenahi barang-barangnya dan meninggalkan Hutabagasan dan menuju Huta Nabolon.Sesampainya di Huta Nabolon Sait Ni Huta, ditunjuklah Sopo tempat panampungan sementara Nommensen. Di Sait Ni Huta memang sulit mendapatkan tanah untuk perkampungan, karena Sait Ni Huta ini dikelilingi oleh sawah, hanya ada sedikit tanah berpasir di tepi sungai Sigeaon, tanah inilah yang diberikan kepada Nommensen untuk membangun rumahnya.

\subsubsection{Masa Penginjilan Nommensen di Tanah Batak \\ Huta Dame adalah} perkampungan pertama yang dibangun Nommensen untuk menampung orang Batak yang tertindas di wilayah Silindung sekaligus menjadi pusat 
penyebaran agama Kristen pertama di Tanah Batak. Dilokasi ini pula Nommensen membangun gereja Dame, yakni Gereja pertama di Silindung yang didirikan pada tahun 1864 (Artista 2012:8)

Singkatnya satu tahun kemudian, tepatnya pada tanggal 27 Agustus 1865, Nommensen dapat melakukan pembabtisan pertama kepada satu orang Batak. Kemudian Raja Pontas Lumban Tobing yang dulunya sempat menolak Nommensen, meminta agar dia dan keluarganya dibaptis juga dan pada saat itu juga Raja Pontas meminta supaya Nommensen pindah dari Huta Dame ke Pearaja. Setelah Raja Pontas dan keluarganya masuk Kristen, masyarakat Silindung makin banyak masuk Kristen.

Nommensen tetap bersiteguh mengenai cita-cita dengan misinya supaya orang Batak Utara harus mengenal Yesus Kristus. Selanjutnya Nommensen pindah ke Pearaja, dan di Pearaja beliau mendapat tanah dari Raja Pontas, di tanah ini beliau mendirikan rumah dan gereja (Arifin 2011:39) ia mendirikan gedung gereja, sekolah, dan rumahnya di Pearaja dan hingga kini, Pearaja tetap menjadi pusat Gereja HKBP.

Pada waktu Nommensen pidah ke Pearaja Tarutung, jemaat gereja Dame selalu mengikuti kebaktian di Pearaja, karena gereja Dame yang di bangun Nommensen sudah rusak karena selalu di genangi air karena banjir di Aek Sigeaon Namun setelah tahun 1880, seusai Nommensen pindah ke Toba, jemaat gereja Dame tidak lagi pergi ke Pearaja untuk kebaktian, karena gereja Dame tidak bisa lagi dipakai untuk kebaktian maka para tokoh/orang tua di Sait Ni Huta mengadakan rapat besar dan bertekad untuk membangun gereja yang
baru.Karena di Huta Dame sering banjir, maka gereja dipindahkan ke Hutanabolon, dekat sopo tempat Nommensen dulu ditempatkan Raja Amandari, dan setelah gereja dibangun disana digantilah nama Hutanabolon menjadi Huta Gereja.

Sejalan dengan pertumbuhan Gereja di Silindung, Nommensen membuka Sekolah Guru di Pansur Napitu.Lulusan sekolah ini dijadikan menjadi guru Injil dan Guru Sekolah.Di kemudian hari, sekolah ini dipindahkan ke Sipaholon.Kemudian, Nommensen membuka pos Penginjilan baru di Sigumpar.Dari sanalah dia menyebarkan Injil bersama para pembantunya ke seluruh Toba Holbung dan Samosir.

Ketika diberi izin oleh pemerintah kolonial, maka RMG menunjuk Nommensen untuk membuka pos zending baru di Silindung. Kehadiran zending ditantang oleh sebagian raja dan juga oleh sebagian besar penduduk karena mereka takut akan terkena bencanajika menyambutseorang asing yang tidak memelihara adat. Selain itu, sikap menolak para raja disebabkan pula oleh kekhawatiran bahwa dengan kedatangan orang-orang kulit putih ini menjadi perintis jalan bagi pemerintahan Belanda yang berkuasa pada waktu itu

Kehadiran para misionaris tidak disetujui oleh sebagian raja, terutama mereka yang berpihak pada Raja Si Singamangaraja ke-XII, maka di bulan Januari 1878, maka pada masa itu Singamangaraja sebagai raja yang, menurut pengakuannya sendiri, memiliki kedaulatan atas Silindung, memberi ultimatum kepada para zendeling RMG agar segera meninggalkan Silindung. Kemudian pada akhir Januari, Nommensen meminta kepada 
pemerintah kolonial Belanda untuk mengirimkan bantuan tentara untuk segera menaklukkan Tanah Batak yang pada saat itu masih merdeka. Pada tahun 1878, Belanda mengirim pasukan pertama di bawah pimpinan Kapten Scheltens bersama dengan Kontrolir Hoevell menuju Pearaja dan kedatangan mereka disambut oleh Nommensen.Berkisar antara Februari hingga Maret, 380 pasukan tambahan dan 100 narapidana didatangkan dari Sibolga. Februari 1878, ekspedisi militer untuk menumpaskan pasukan Singamangaraja ke-XII dimulai. Penginjil Nommensen dan Simoneit mendampingi pasukan Belanda selama ekspedisi militer ini berlangsung yang dikenal sebagai Perang Toba I. Nommensen dan Simoneit menjadi penunjuk jalan dan penerjemah bagi Belanda, kemudian Nommensen malah dianggap ikut berperan dalam menentukan kampung-kampung mana yang akan dibakar. Sesudah ekspedisi militer berakhir, puluhan kampung, termasuk markas Singamangaraja di Bakara dibumihanguskan.

Setelah menguasai Silindung dan Toba pada Perang Toba I, Batakmission (zending Batak) mengalami kemajuan dengan pesat, khususnya di daerah Utara. Hal ini menjadi moment kebangkitan Nommensen yang berhasil meyakinkan ratusan raja untuk berhenti mengadakan perlawanan. Tentunya, ada saat Nommensen di pertanyakan tentang adakah keberpihakan dengan pihak Belanda, akan tetapiNommensen mampu meyakinkan raja-raja Batak pada masa itu, bahwa ia bukan kaki tangan Belanda dan kedatangannya bukan untuk tujuan Belanda melainkan untuk memberitakan Injil di tanah Batak. Hal ini tampak dalam tindakan keseharian Nommensen bagi orang-orang Batak waktu itu. Contoh beberapa raja yang akhirnya bersikap positif ialah Raja Pontas Lumbantobing (Sipahutar), Ompu Hatobung (di Pansur Napitu), Kali Bonar (di Pahae), Ompu Batu Tahan (di Balige), dan lainnya.

\subsubsection{Masa Akhir Pengabdian Nommensen \\ Tahun $1880 \quad$ Nommensen} meninggalkan Pearaja dan melanjutkan misinya kedaerah Toba Laguboti dan memberikan pengabaran Injil ke daerah seperti Bahal Batu, Paranginan, Lintong Ni Huta, Sipahutar, Laguboti, Palipi, Mogang, Pangururan, Samosir dan Sigumpar.

Nommensen meninggal di Sigumpar pada 23 Mei 1918 dan di kebumikan di Sigumpar tanggal 24 Mei 1918.Beliau mengabdi di Tanah Batak selama 57 tahun. Nommensen meninggal genap usia 84 tahun. Luar biasa jasa dan pengabdian beliau untuk Tanah Batak, dan memang hidupnya hanya Tanah Batak (Tapian Nauli) Sigumpar, Porsea, 20 km dari Parapat, kota wisata dunia, di tepian Danau Toba, Danau terindah di dunia. Tentu sangat pantas, memugar makam Dr Nommensen, dijadikan menjadi taman rohani dan objek wisata.

Demikianlah peristiwa pada tahun 1863, ketika missionaris agama Kristen asal Jerman itu mengawali babak kehidupan baru bagi orang-orang Batak yang belum mengenal agama Kristen, hingga Nommensen wafat tanggal 23 Mei 1918, dan dimakamkan di desa Sigumpar sekitar $60 \mathrm{Km}$ utara Tarutung. Setelah 132 tahun berlalu, barulah pada tahun 1993/1994, pada masa kepemimpinan Bupati RE Nainggolan sebagai penghormatan dan penghargaan atas jasa- jasa DR. Ingwer Ludwig Nommensen yang menyebarkan 
agama Kristen, untuk mengenangnya maka Pemda Tapanuli Utara membangun wisata rohani Salib Kasih yang tinggi nya mencapai 31 meter di puncak bukit Siatas Barita.

\section{SIMPULAN}

Hasil kajian ini menunjukkan bahwa dari segi daya tarik atau atraksi wisata maka wisata religi tergolong kepada buatan manusia (Man made), manusia membuat tempat pariwisata, atau dalam hal ini keperdulian pemerintah kabupaten tapanuli utara membangun monumen, untuk mengenang misionaris Kristen yang bernama Nommensen tujuannya disamping untuk mengenang peristiwa penyebaran agama Kristen di tanah Batak tetapi juga sebagai tempat pariwisata, maka pemerintah tapanuli utara membangun monumen yang dinamai pariwisata Salib Kasih Tarutung yang terletak di provinsi Sumatera utara kabupaten tapanuli utara, ibukota Tarutung, kecamatan siatas barita desa simorangkir julu.

\section{DAFTAR PUSTAKA}

Anonimous. (1988). GBHN Ketetapan MPR RI Nomor II/MPR/1988. Garis-garis Besar Haluan Negara.

Artista. 2012. "Wisata Rohani Di Silindung". Edisi 53Tahun V Juni.

Graburn, Nelson H. H. ed. 1976.Ethnic and Tourist Art: Cultural Expression From The fourth World. Berkeley, LA: University of California Press.
Hutajulu Rithaony. 1997.Pariwisata Etnik :Dampak Pariwisata Terhadap Upacara Tradisional Pada Masyarakat Batak Toba. Jurnal Seni Pertunjukan Indonesia.T h. VIII.

Hutasoit.Hotmaida.T. - Simanjuntak. 1993. I.L. Nommensen Sang Penabur Di Tanah Batak. PT BPK GUNUNG MULIA.

Pasaribu Arifin, 2011. "Tarutung Kota Wisata Penuh Sejarah" Horas, Edisi $142.10 \quad-\quad 30$ September.

Pendit, Nyoman S. 1986. Ilmu Pariwisata: Sebuah Pengantar Perdana. Jakarta: PT. Pradya Paramita.

Siahaan Edward. 2003. "Tapanuli Utara The Beautiful land".Seni Jurnal PemerintahKabupaten Tapanuli Utara.

Simanjuntak PWT, 2011. "Berkat Sekolah Zending, Tano Batak Maju" Horas, Edisi 135. 5 - 20 Maret.

Soejono Soeprapto. 1997. Kenyataan dan Harapan: Dampak Industri Pariwisata Pada Seni Pertunjukan Jurnal Seni Pertunjukan Indonesia. $\mathrm{T} \mathrm{h}$. VIII.

Spillane, James J. 1987. Ekonomi Pariwisata, Sejarah dan Prospeknya. Yogyakarta: Kanisius

http://www.travbuddy.com/Salib-Kasihv174418

http://www.waspada.co.idtaputkab.go.id 